\title{
Review
}

Molecular

Neuropsychiatry

Published online: November 7, 2018

DOI: 10.1159/000493941

\section{VRK2, a Candidate Gene for Psychiatric and Neurological Disorders}

\author{
Ming Li ${ }^{a, b}$ Weihua Yue ${ }^{c, d}$ \\ ${ }^{a}$ Key Laboratory of Animal Models and Human Disease Mechanisms of the Chinese Academy of Sciences and \\ Yunnan Province, Kunming Institute of Zoology, Kunming, China; ${ }^{b}$ CAS Center for Excellence in Brain Science and \\ Intelligence Technology, Chinese Academy of Sciences, Shanghai, China; ${ }^{C}$ Peking University Sixth Hospital/Institute \\ of Mental Health, Beijing, China; ${ }^{d}$ Key Laboratory of Mental Health, Ministry of Health (Peking University) and \\ National Clinical Research Center for Mental Disorders (Peking University Sixth Hospital), Beijing, China
}

\section{Keywords}

VRK2 - Genome-wide association study · Schizophrenia .

Major depressive disorder · Biological mechanism

\begin{abstract}
Recent large-scale genetic approaches, such as genomewide association studies, have identified multiple genetic variations that contribute to the risk of mental illnesses, among which single nucleotide polymorphisms (SNPs) within or near the vaccinia related kinase 2 (VRK2) gene have gained consistent support for their correlations with multiple psychiatric and neurological disorders including schizophrenia (SCZ), major depressive disorder (MDD), and genetic generalized epilepsy. For instance, the genetic variant rs1518395 in VRK2 showed genome-wide significant associations with $\mathrm{SCZ}(35,476$ cases and 46,839 controls, $p=3.43$ $\left.\times 10^{-8}\right)$ and MDD $(130,620$ cases and 347,620 controls, $p=$ $\left.4.32 \times 10^{-12}\right)$ in European populations. This SNP was also genome-wide significantly associated with SCZ in Han Chinese population (12,083 cases and 24,097 controls, $p=3.78 \times$ $\left.10^{-13}\right)$, and all associations were in the same direction of allelic effects. These studies highlight the potential roles of VRK2 in the central nervous system, and this gene therefore
\end{abstract}

\section{KARGER}

(C) 2018 S. Karger AG, Basel

E-Mail karger@karger.com

www.karger.com/mnp might be a good candidate to investigate the shared genetic and molecular basis between SCZ and MDD, as it is one of the few genes known to show genome-wide significant associations with both illnesses. Furthermore, the VRK2 gene was found to be involved in multiple other congenital deficits related to the malfunction of neurodevelopment, adding further support for the involvement of this gene in the pathogenesis of these neurological and psychiatric illnesses. While the precise function of VRK2 in these conditions remains unclear, preliminary evidence suggests that it may affect neuronal proliferation and migration via interacting with multiple essential signaling pathways involving other susceptibility genes/proteins for psychiatric disorders. Here, we have reviewed the recent progress of genetic and molecular studies of VRK2, with an emphasis on its role in psychiatric illnesses and neurological functions. We believe that attention to this important gene is necessary, and further investigations of $V R K 2$ may provide hints into the underlying mechanisms of SCZ and MDD.

(c) 2018 S. Karger AG, Basel
Ming Li, PhD

Kunming Institute of Zoology

Chinese Academy of Sciences

32 Jiao-Chang Donglu, Kunming, Yunnan 650223 (China)

E-Mail limingkiz@ mail.kiz.ac.cn

Weihua Yue, $\mathrm{PhD}, \mathrm{MD}$

Institute of Mental Health/The Sixth Hospital

Peking University

51 Hua Yuan Bei Road, Beijing 100191 (China)

E-Mail dryue@bjmu.edu.cn 


\section{Introduction}

Schizophrenia (SCZ) and major depressive disorder (MDD) are seriously disabling public health problems. The worldwide lifetime prevalence and incidence of SCZ are $0.30-0.66 \%$ and $10.2-22.0$ per 100,000 personyears, respectively, if its diagnostic category is considered in isolation [1-3], and this illness shows strong heritability (around 0.80 ) based on previous twin and family studies $[1,4-6]$. A previous review reported that MDD has a 12 -month prevalence of $6.6 \%$ and a lifetime prevalence of $16.2 \%[7,8]$. Meanwhile, the lifetime incidence of MDD (broad definition) in the United States is more than $12 \%$ in men and $20 \%$ in women $[8,9]$. MDD also shows substantial heritability (approx. 0.37) $[9,10]$ and polygenic inheritance $[11,12]$. However, promising genetic risk candidates for SCZ and MDD had not been well implicated until the emergence of recent largescale genome-wide association studies (GWAS) [1321]. GWAS is believed to be an ideal approach for studying common genetic variations across the genome, given its key feature that no a priori hypotheses are established [22]. Indeed, GWAS of psychiatric disorders have led to the identification of multiple novel risk variants with known or unknown function relevant to the biology of illnesses [23-25], and substantial progress has been obtained toward understanding the genetic architecture and molecular pathogeneses (e.g., dendritic spine pathology) of these psychiatric disorders [26, 27]. Among the risk candidates discovered through SCZ and MDD GWAS studies [13-20], VRK2 (vaccinia-related kinase 2) is one of the few genes showing consistent genome-wide significant associations with both disorders. In addition, this gene has been implicated in a variety of neurological disorders, further supporting its potential roles in the central nervous system. However, despite strong genetic evidence and a relatively rudimental understanding of the biological mechanisms of VRK2 in SCZ and MDD susceptibility, a systematic overview of existing evidence to depict the potential involvement and relevant biological mechanisms of this gene in these illnesses is lacking. Thus, we examined recent discoveries regarding the role of VRK2 in psychiatric and neurological disorders, including genetics, molecular biology, and neurophysiology to propose recommendations for future research.

\section{Identification of VRK2 Variants in Psychiatric Disorders among World Populations}

VRK2 was first implicated in psychiatric disorders by Stefansson et al. [28]. By conducting a GWAS study, the authors reported several risk polymorphisms conferring risk of SCZ in 47,536 European subjects [28]. The single nucleotide polymorphism (SNP) rs2312147, which is located in the intron 1 of VRK2 (Fig. 1a), was identified as a potential SCZ risk SNP $\left(p=3.00 \times 10^{-7}\right)$, although it did not achieve conventional genome-wide significance (which is $p=5.00 \times 10^{-8}$ ). Later, Steinberg et al. [29]) confirmed the association between rs2312147 and SCZ in larger European samples $\left(n=60,742, p=1.9 \times 10^{-9}\right)$. Following these, the Irish Schizophrenia Genomics Consortium and the Welcome Trust Case Control Consortium 2 further replicated this significant association of rs 2312147 and SCZ in a European GWAS [30]. These series of studies motivated researchers worldwide to pay attention to the genetic risk for SCZ conferred by VRK2 polymorphisms, and replication studies in populations other than Europeans were also conducted [31-33]. For example, Li et al. [34] replicated the association between rs2312147 and SCZ in independent Asian samples $(n=6,565, p=$ $4.24 \times 10^{-4}$ ). More recently, several meta-analytic studies have further confirmed the role of this SNP in the risk of SCZ in both East Asians and Europeans [35, 36]. In addition, in the recent PGC2 SCZ GWAS, rs2312147 again displayed genome-wide significance $(35,476$ cases and 46,839 controls, $p=2.02 \times 10^{-8}$, Fig. 2) [13]. These results are particularly intriguing as the effect sizes of rs 2312147 for SCZ are similar between European and Asian populations, suggesting that it is likely an authentic risk variant for SCZ in general populations.

In addition to rs2312147, other SNPs in the VRK2 gene have also been found to be associated with SCZ in both East Asian and European populations. For example, in a recent SCZ GWAS in Han Chinese population, a genetic variant (rs1518395) in the intron 1 of VRK2 showed a genome-wide significant association in a total of 12,083

Fig. 1. a Schematic of mRNA structure of $V R K 2$ isoforms and locations of representative SNPs. $\mathbf{b}$ mRNA expression of VRK2 isoforms in diverse human tissues and cells from GTEx dataset [44]. c mRNA expression of VRK2 gene in brain single-cell RNA-seq dataset (GSE67835) [84]. d Schematic of domain structure of predicted Vrk2 protein. The source of this figure was previous literature $[104,175]$. SCZ, schizophrenia; MDD, major depressive disorder; GGE, genetic generalized epilepsy; OPC, oligodendrocyte progenitor cell.

(For figure see next page.) 


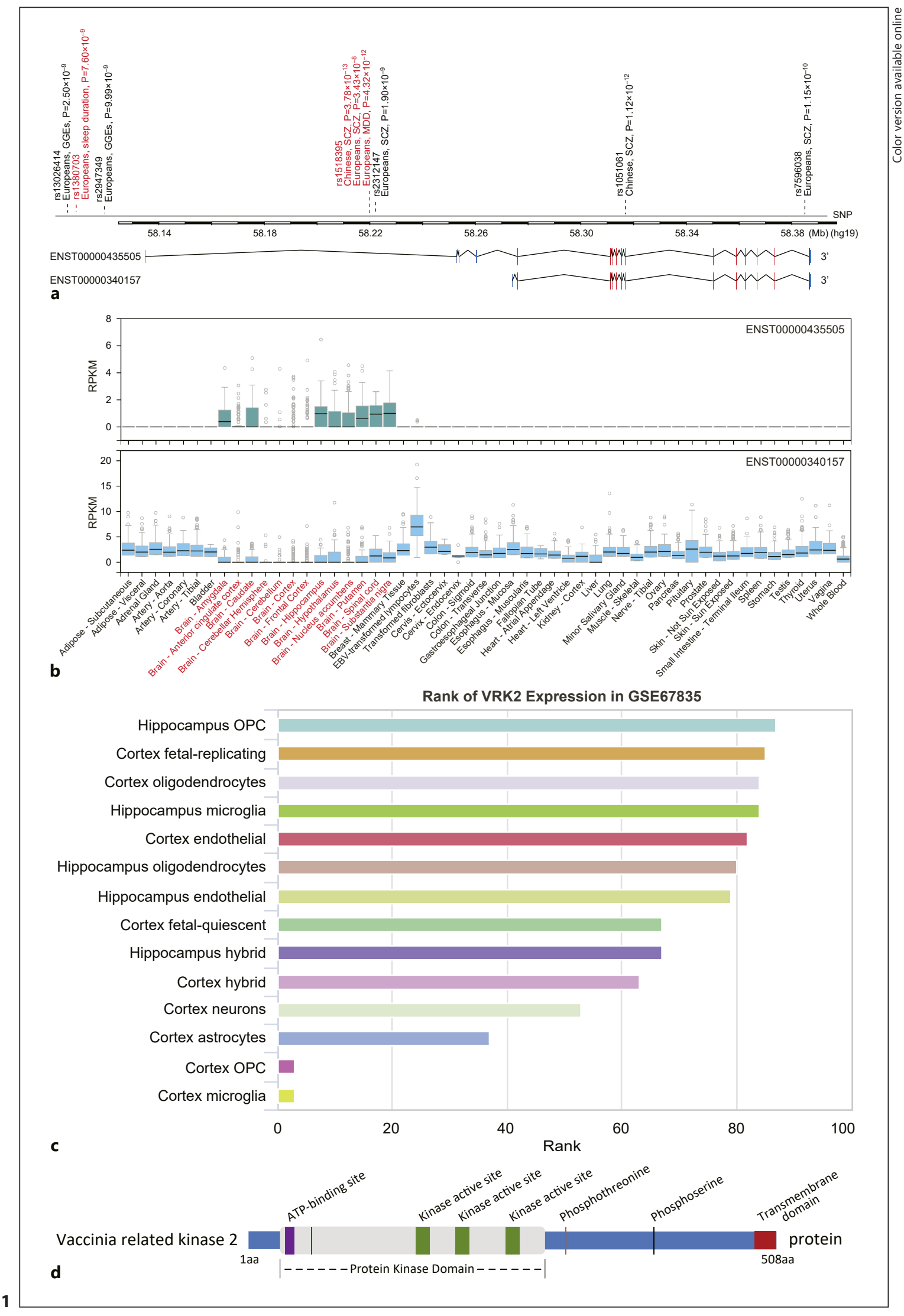

VRK2 in Psychiatric and Neurological 


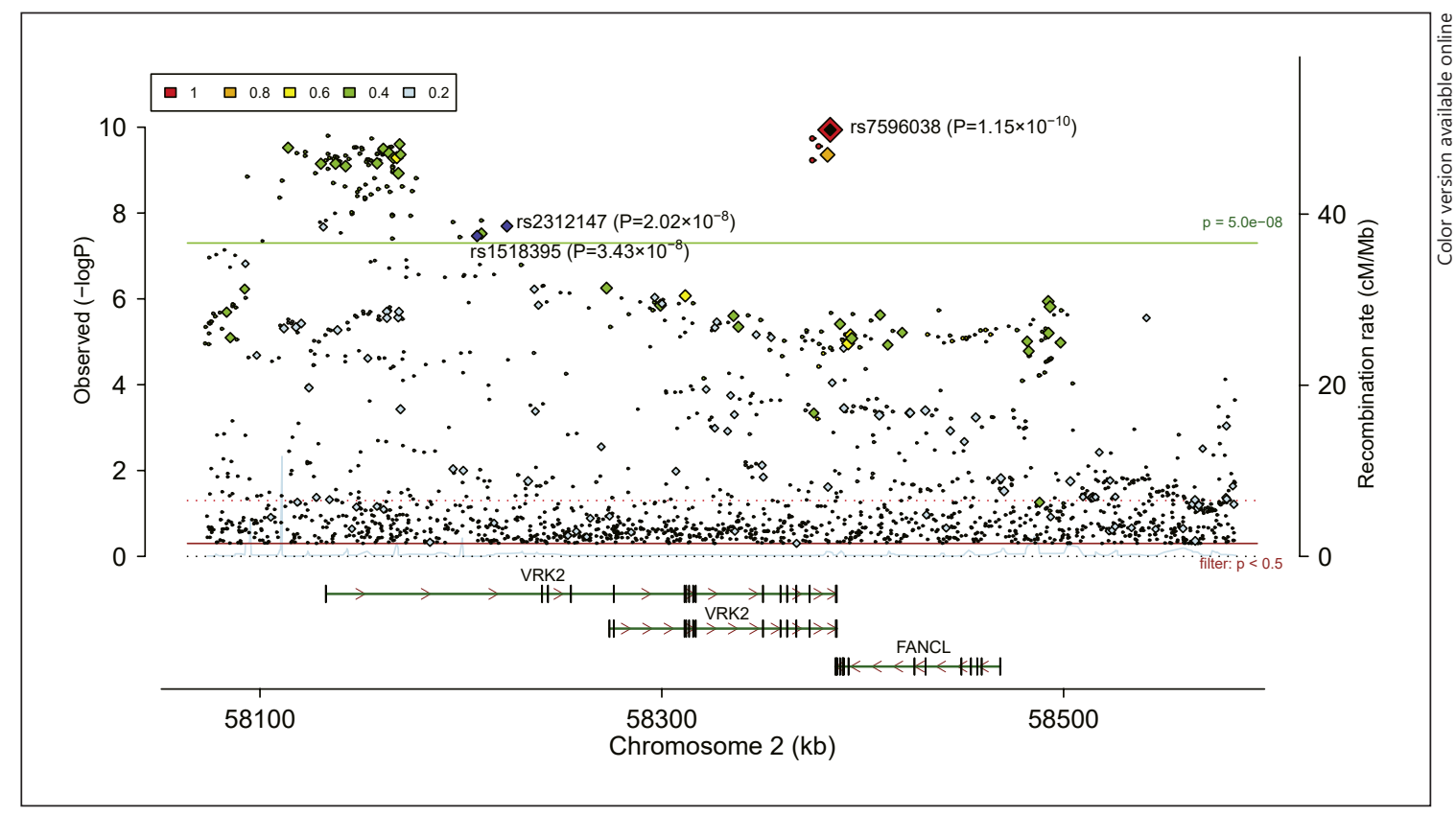

Fig. 2. Associations of VRK2 common variants with schizophrenia in PGC2 genome-wide association studies of European ancestry [13]. This figure was made using LocusZoom [176].

cases and 24,097 controls $\left(p=3.78 \times 10^{-13}, \mathrm{OR}=1.160\right.$ for $\mathrm{G}$ allele) [15]. This is one of the most significant SNPs for SCZ in Chinese, and this SNP was also genome-wide significantly associated with SCZ in European populations $\left(35,476\right.$ cases and 46,839 controls, $p=3.43 \times 10^{-8}$, $\mathrm{OR}=1.061$ for $\mathrm{G}$ allele, Fig. 2) [13]. More interestingly, in a recent GWAS of MDD in European populations (130,620 cases and 347,620 controls), rs1518395 again showed genome-wide significant associations with MDD ( $p=4.32 \times 10^{-12}, \mathrm{OR}=1.034$ for G allele) [14], and the same allele of rs1518395 increased the risk of both SCZ and MDD, suggesting the involvement of the variant(s) in VRK2 in a broad spectrum of mood-psychosis conditions, at least in the European populations. More importantly, rs1518395 is also one of the few SNPs showing genome-wide significant associations with SCZ in both European and Chinese populations; such observations greatly enhance our understanding of the shared genetic basis of SCZ between populations. We retrieved the distributions of rs1518395 in 53 populations worldwide using the HGDP Selection Browser (http://hgdp.uchicago. edu/) [37-39], and its allelic frequencies between East Asians and Europeans were similar (Fig. 3). We then examined the linkage disequilibrium (LD) between rs1518395 and nearby SNPs in East Asian and European populations using the SNAP website (http://archive. broadinstitute.org/mpg/snap/ldplot.php) and identified sharp differences in the LD pattern of this genomic region between the two populations (Fig. 4). Briefly, there were more SNPs in high LD $\left(r^{2}>0.8\right)$ with rs1518395 in Europeans, and the linked SNPs spanned a wide region, while in East Asians, there were fewer SNPs in strong LD with rs1518395 covering a smaller genomic region (Fig. 4). Nevertheless, this trans-ethnic analysis added further evidence for the involvement of rs1518395 (or its LD SNPs) in the risk of psychiatric disorders.

Notably, rs1518395 and rs2312147 are in high LD ( $r^{2}=1.000$ in Europeans and $r^{2}=0.876$ in East Asians), and both SNPs are located in the noncoding region (Fig. 1a). Prior evidence has suggested that noncoding SNPs might exert their function by affecting gene expression levels [40-43], and we thus examined the associations of rs2312147 and rs1518395 with nearby gene expression using the existing expression quantitative trait loci (eQTL) datasets, such as GTEx [44], Braineac [45], and BrainCloud [46]. However, no significant associations were observed, and the potential impact of those risk SNPs is still unclear.

In addition to rs 1518395 and rs2312147, several other SNPs in low to moderate LD in the VRK2 gene are also associated with SCZ. For instance, in the PGC2 GWAS of SCZ using samples mainly from European populations 
Fig. 3. Global distributions of rs1518395 in 53 world populations from HGDP dataset [37-39].

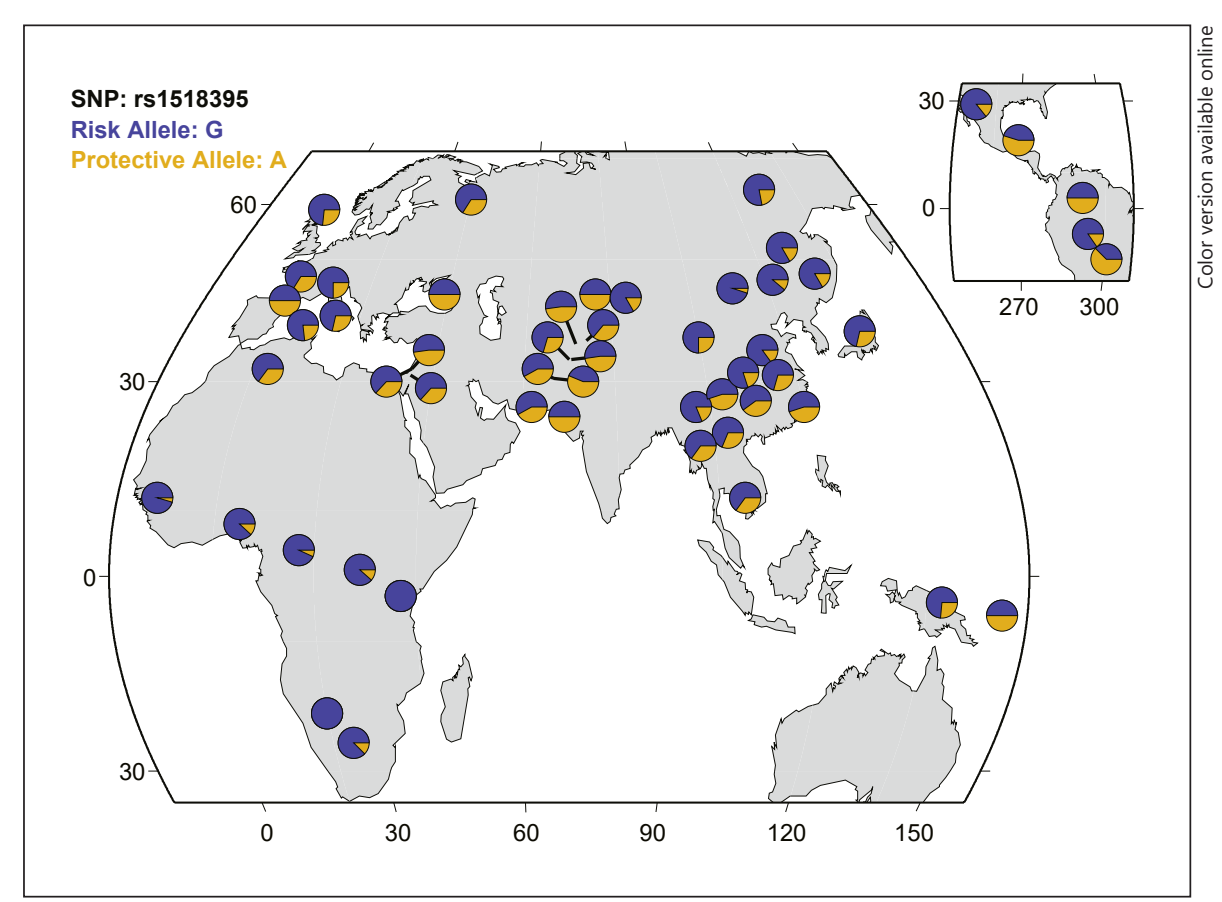

[13], multiple genomic variants in low to high LD with rs1518395 showed genome-wide significant associations. Rs7596038, a SNP located $175 \mathrm{~kb}$ from rs1518395 and in moderate LD $\left(r^{2}=0.500\right.$ in Europeans, and $r^{2}=0.288$ in East Asians) showed the strongest association with SCZ among VRK2 regions ( $p=1.15 \times 10^{-10}$, Fig. 2); rs7596038 is located in the intron region of VRK2 and is predicted to be nonfunctional through the epigenomic analyses using ENCODE data [47], but further studies are necessary to examine its functional impact. Furthermore, in a recent GWAS of SCZ in Han Chinese populations, Yu et al. [48] reported that rs1051061 $\left(r^{2}=0.224\right.$ with rs1518395 in Europeans, $r^{2}=0.178$ with rs 1518395 in East Asians) in an exon of $V R K 2$ was genome-wide significantly associated with SCZ in a total of 8,723 cases and 12,813 controls $\left(p=1.14 \times 10^{-12}\right.$, see Fig. 1a). Although this SNP did not achieve genome-wide significance in European populations (35,476 cases and 46,839 controls, $p=1.26 \times 10^{-6}$ ) [13], the same direction of allelic effects was observed in both Europeans and Chinese, further strengthening the link between VRK2 and SCZ. Overall, these data suggest that there are (at least partially) independent association signals for SCZ within VRK2 in global populations.

Additionally, the association between VRK2 and bipolar disorder (BPD) has also been implicated in a recent BPD GWAS conducted in European populations [49]. Briefly, an intergenic variant rs57681866 near VRK2, rather than the earlier reported SCZ-associated SNP rs 1518395 (these two SNPs are $232.3 \mathrm{~kb}$ away from each other, and in low LD in Europeans $\left.\left[r^{2}=0.001\right]\right)$, showed genome-wide significant association $\left(p=5.00 \times 10^{-8}\right)$ with the illness in the discovery stage of this study $(20,352$ cases and 31,358 controls). However, the association between rs57681866 and BPD was not observed in the replication stage of this GWAS $(9,412$ cases and 137,760 controls) [49]. This leaves questions to be further investigated: Is VRK2 truly associated with BPD? Is the nonsignificant result during replication stage attributed to the limited sample size of BPD patients? Expanded analyses including more subjects might provide clues.

While the association of VRK2 with psychiatric disorders is supported by convincing evidence, the precise impacts of the risk SNPs on neuronal function and brain development remain unclear. Recent studies suggest that changes in regional brain structures and functions are core features of SCZ [50-54] and MDD [55-59], and neuroimaging approaches may provide clues into the underlying pathophysiology of these illnesses. In fact, it is proposed that there are intermediate phenotypes reflecting alterations in brain structure and function in psychiatric patients and their unaffected relatives compared to unrelated healthy individuals [60]. These intermediate phenotypes are assumed to involve the same biological pathways as the illness but to relate more closely 


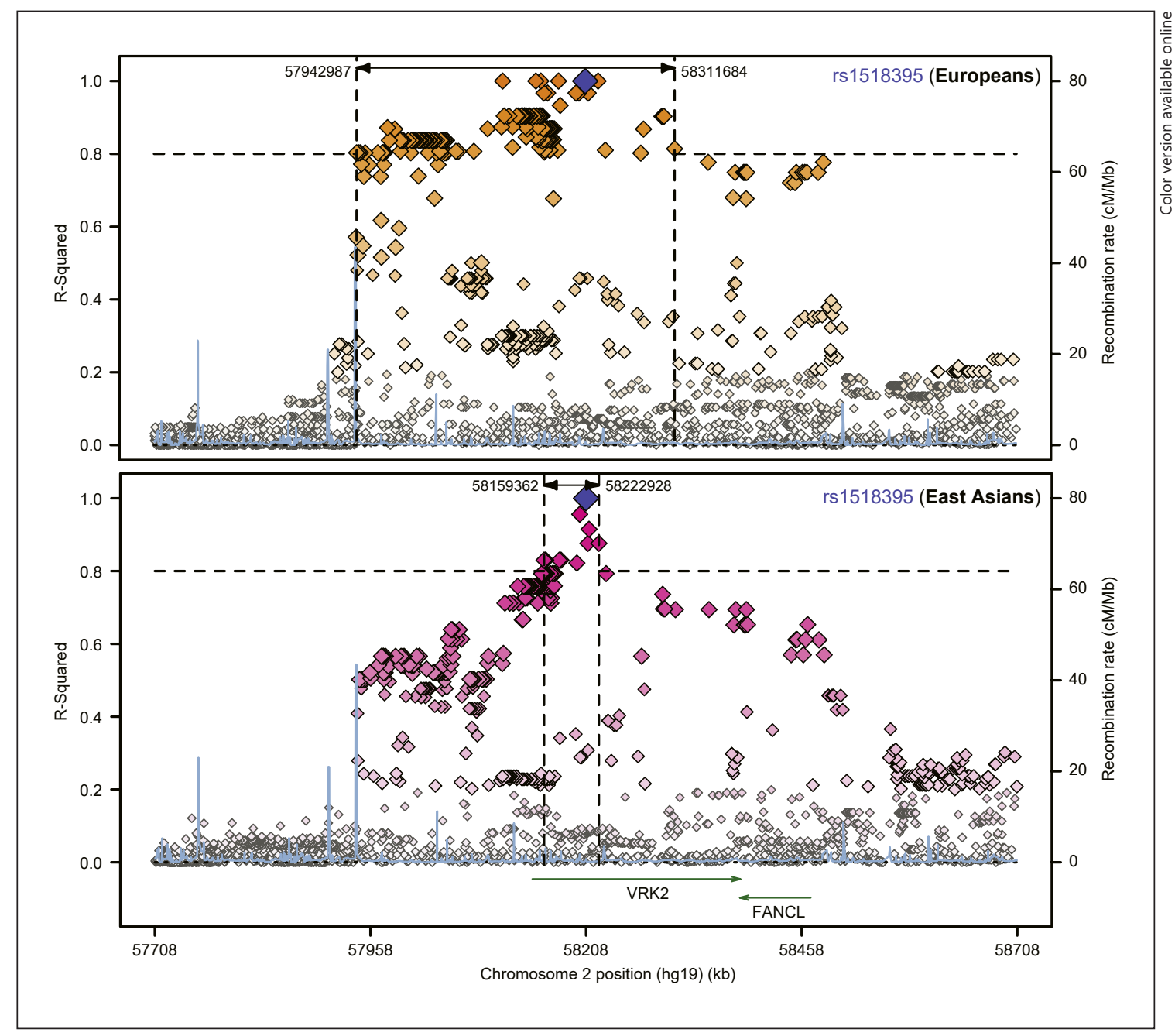

Fig. 4. Comparisons of rs1518395 LD SNPs between European and East Asian populations. This figure was obtained from the SNAP website.

to the effects of relevant genes [61-65]. Recent studies of several psychiatric candidate genes including ZNF804A [66-68] and CACNA1C [69-72] have already demonstrated the validity and reliability of this approach. We previously also analyzed the association between VRK2 SNPs and brain phenotypes related to psychiatric disorders [34] and found that the psychiatric risk allele [C] in rs2312147 was associated with reduced total brain volume and white matter volume in healthy individuals, which was in line with clinical characteristics in the brains of psychiatric patients compared with healthy controls [73]. This finding was further supported by Sohn et al. [74], as they reported significant differences in the white matter connectivity between rs 2312147 CC and CT/TT genotype groups of SCZ patients for many brain regions. These data provided initial evidence for the effects of VRK2 on white matter development, and investigations dissecting the underlying biological mechanisms and etiological relevance in psychosis and mood disorders are necessary.

\section{VRK2 and Genetic Generalized Epilepsies}

In addition to SCZ and MDD, variants in VRK2 have been implicated in genetic generalized epilepsies (GGEs). GGEs have a lifetime prevalence of $0.3 \%$ [75] and account for $20-30 \%$ of all epilepsies [76]. In 2012, the EPICURE Consortium conducted a two-stage GWAS of 3,020 patients with GGEs and 3,954 controls of European ancestry 


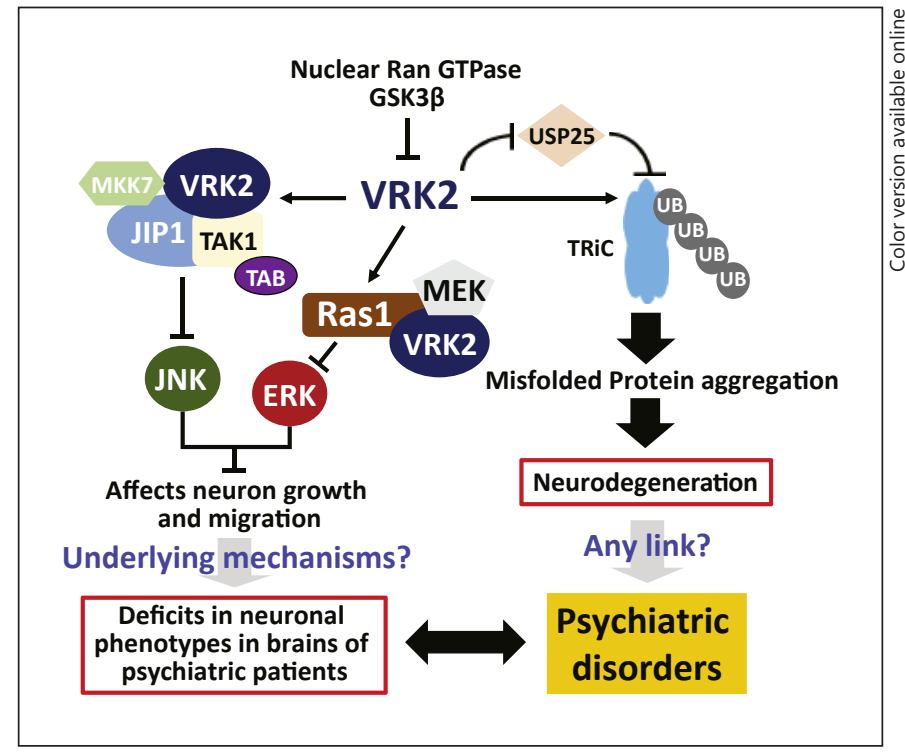

Fig. 5. A hypothesized molecular mechanism for VRK2 in the pathogenesis of psychiatric disorders. This figure was made according to previous published studies regarding the function of Vrk2 and its interactions with other molecules, such as Erk [104, $105,141,142]$.

and revealed genome-wide significant association signals for GGEs at 2p16.1 ( $r$ 13026414, $p=2.5 \times 10^{-9}$, see Fig. 1a) [75]. The associated chromosomal segment consists of $\sim 900 \mathrm{~kb}$ encompassing VRK2 and the gene encoding the Fanconi-anemia-complementation L polypeptide (FANCL). Notably, in an independent GWAS sample set, rs13026414 was found to be nominally significantly associated with GGEs at $p=7.0 \times 10^{-3}$ [77]. In this later GWAS, a meta-analysis of 2,606 cases and 18,990 controls revealed that a variant rs 2947349 in close proximity to the transcription start site of the long VRK2 isoform was the most significant SNP for GGEs $\left(p=9.99 \times 10^{-9}\right.$, see Fig. 1a) [77]. Both studies suggested that VRK2 was likely a risk factor for GGEs. Interestingly, the psychiatric risk SNP rs2312147 was found to show modest to strong LD $\left(r^{2}: 0.25-0.87\right)$ with the susceptibility variants of GGEs at 2p16.1 and showed a strong signal with GGEs (rs2312147, $p=2.3 \times 10^{-6}$ ) [77]. Collectively, these overlapping association signals indicate that VRK2 may be involved in the shared etiological and genetic basis of psychiatric disorders and GGEs. However, the directions of the allelic effects were inconsistent, as the risk allele at rs2312147 of psychiatric disorders actually conferred protective effects against GGEs [77]. This result was in contrast with epidemiologic evidence of the prevalent comorbidities of psychiatric disorders (such as mood, anxiety, and psychotic disorders) and epilepsy [78], and there may be an unidentified complex mechanism underlying this inconsistency that should be elucidated.

\section{VRK2 Expression in Psychiatric Disorders and Epilepsies}

The involvement of the VRK2 gene in the genetic risk and heritability of psychiatric and neurological disorders calls for further characterization of its role in these illnesses. It is suggested that most genetic risk variants contribute to diseases via modulating mRNA expression of susceptible genes [40, 43, 79], and earlier studies have examined the mRNA expression of VRK2 in patients with psychiatric disorders. For instance, Tesli et al. [80] have measured VRK2 mRNA level in the whole blood of 652 European individuals (SCZ, $n=201$; BPD, $n=167$; psychosis not otherwise specified [PNOS], $n=61$; healthy controls, $n=223$ ) and analyzed the difference in expression levels (as stated in their study, "the probe used for measuring VRK2 expression was chosen so as to produce an aggregate measure of expression over all RefSeq transcripts") across diagnostic categories and subcategories. They found that VRK2 mRNA levels differed significantly between the SCZ, BPD, PNOS, and control groups, and pairwise comparisons revealed significantly lower VRK2 mRNA levels in the SCZ group than in healthy controls [80]. Interestingly, they did not observe significant alteration of VRK2 mRNA levels in patients treated with antipsychotics, anticonvulsants, lithium, hypnotics, or psychostimulants [80]. In another study, the authors also compared the peripheral blood VRK2 gene expression (measuring the aggregate expression of all isoforms) in SCZ or epilepsy patients to that of normal subjects; the authors found significant downregulation of VRK2 mRNA levels in SCZ $(p<0.0001)$ and epilepsy $(p=0.008)$ compared with healthy individuals [81]. Collectively, these data suggest that lower VRK2 mRNA in the blood is likely an indicator (or a risk factor) of SCZ and epilepsy, presenting a potential opportunity for the future development of new biomarkers.

As shown in the Ensembl, VRK2 has two primary mRNAtranscripts, alongertranscript(ENST00000435505) with generally lower expression levels that is enriched in the brain, and a shorter transcript (ENST00000340157) that is widely expressed in nonbrain tissues at higher levels (these data have been retrieved from the GTEx dataset, Fig. 1b). Nevertheless, both isoforms encode the same protein. The hypothesis that SCZ and MDD are mental 
illnesses mostly originated from brain dysfunctions, and thus, it is of great interest to clarify whether mRNA levels of VRK2 in the brain tissues from psychiatric individuals exhibit alterations compared with healthy subjects. For this purpose, we performed analyses using data from the Stanley Medical Research Institute (SMRI) dataset (http:// sncid.stanleyresearch.org/) [82]. Compared with healthy controls, VRK2 (aggregate expression of all isoforms) was not significantly altered in the dorsolateral prefrontal cortex region from the brains of patients with SCZ or MDD in this analysis. However, this result does not deny the putative involvement of VRK2 in these illnesses, as the gene may exert its effects in other brain regions such as the hippocampus and amygdala and might also undergo posttranscriptional modulations and thereby contribute to the pathogenesis of the illnesses. To this end, we examined the brain cell types in which the VRK2 was dominantly expressed using scRNASeqDB (https://bioinfo.uth.edu/ scrnaseqdb/index.php), an online single-cell RNA-seq dataset [83]. In this dataset, we utilized the data from GSE67835 [84], which used single-cell RNA-seq on hundreds of cells to capture the cellular complexity at the whole-brain transcriptome level during different developmental stages. Intriguingly, VRK2 is abundantly expressed in the hippocampus oligodendrocyte progenitor cell (OPC), followed by cortex fetal-replicating, cortex oligodendrocytes, hippocampus microglia, and other cells, while this gene is weakly expressed in the cortex OPC and cortex microglia (Fig. 1c) [84]. These data suggest that the VRK2 may exert variable functions in different brain cell types.

\section{VRK2 and Other Congenital Abnormalities}

There has been a consensus that individuals with congenital developmental abnormalities are prone to develop psychiatric disorders later in life $[85,86]$, and the prevalence of major psychiatric illnesses in children with mental retardation is significantly higher than that in general populations [87-89]. Indeed, the etiological contribution of developmental deficits to psychiatric and neurological disorders including SCZ [50, 90], autism [91, 92], MDD $[93,94]$, and potentially BPD [95] have been recognized. A core mechanism underlying this neurodevelopmental hypothesis for psychiatric disorders is impaired brain development, which might also be manifested as a series of congenital abnormalities, such as microcephaly $[96,97]$ and intellectual disability [98]. In fact, several studies have examined the correlation between genetic variants affecting VRK2 and major developmental abnormalities and have revealed a potentially pivotal role for this gene in neurodevelopment.

Chandler et al. [99] reported a novel neurodevelopmental disorder characterized by "congenital microcephaly with severe failure of postnatal brain growth, neonatal onset of intractable seizures associated with lack of developmental progression and death within the first 3 years of life." In a few cases, a homozygous deletion within the 2p16 region, which harbors the gene VRK2, was found to be associated with these phenotypes. Intriguingly, this region was later highlighted, respectively, in studies of idiopathic intellectual disability and other related developmental disorders by Rajcan-Separovic et al. [100] and de Leeuw et al. [101]. In their studies, deletions encompassing VRK2 within this genomic region were consistently identified in intellectually disabled individuals, suggesting a potential contribution by VRK2 to these phenotypes. However, whether VRK2 actually accounts for these developmental deficits remains to be clarified.

In addition to the aforementioned developmental problems, longitudinal studies have revealed a significant correlation between sleeping problems and behavioral and emotional abnormalities (including depression and anxiety) that develop later in life [102]. Interestingly, Jones et al. [103] found that two conditionally independent SNPs near the VRK2 gene, $r$ rs $1380703\left(p=7.6 \times 10^{-9}\right.$, see Fig. 1a) and rs17190618 $\left(p=1.2 \times 10^{-9}\right)$, exhibited genome-wide significant associations with sleep duration using the self-reported chronotype data from 89,283 individuals of European ancestry, which were replicated in another 128,266 British individuals. These data have provided preliminary but enlightening evidence for the involvement of $V R K 2$ in neurological activities and likely for brain function.

\section{Functions of VRK2 in the Neurological System}

While the genetic associations between variants in $V R K 2$ and a variety of psychiatric and neurological conditions have been reported, the potential roles of VRK2 and its protein product, the vaccine-related serine/threonine kinase 2 (Vrk2), are largely unknown. However, studies analyzing their structure and function have been continuously progressing $[104,105]$ and have provided valuable implications for future investigations.

The VRK2 gene is located on human chromosome 2 p16.1 and codes for a serine/threonine kinase of the ca- 
sein kinase I group (Fig. 1d) [106]. Vrk2 has two protein isoforms: Vrk2A with a transmembrane domain that is mainly anchored in the endoplasmic reticulum and the mitochondria, and Vrk2B, which lacks the transmembrane domain and is present in both the cytosol and nucleus [107]. A detailed comparison of these two isoforms is beyond the scope of the current review. Since a majority of functional studies on Vrk2 in the psychiatric field either do not differ between these two isoforms or report an important function of Vrk2A, this review will focus on the function of Vrk2A (referred as Vrk2 in the following discussion). Earlier studies on the function of Vrk2 were primarily based on the nature of this protein as a kinase and were largely conducted through comparative analyses of its structurally similar protein, Vrk1 [106]. For example, a recent study showed that Vrk2 is a transmembrane kinase in the nuclear envelope (NE) and phosphorylates a highly dynamic chromatin-binding protein $\mathrm{BAF}$ (barrier to autointegration factor), which will likely affect NE reassembly and chromatin changes during cell cycle [108]. Also, Vrk2 was initially proposed to play potential roles in cell proliferation and survival [106]. The enriched expression of this protein in organs containing highly proliferative cells (e.g., fetal liver, skeletal muscles, pancreas, heart, peripheral blood leukocytes, and the testis) further supported this hypothesis [106, 109]. Indeed, researchers have found that the expression levels of Vrk2 predict tumor growth and prognostic responses in patients with astrocytoma [110] and rectal cancer [111]. In addition, there is evidence that higher Vrk2 levels confer protection against apoptosis and promote cell survival [112], while overexpression of Vrk2 in human neuroblastoma (SH-SY5Y) cells also reduced neurite outgrowth induced by retinoic acid [113]. These functions of Vrk2 have been linked to SCZ and MDD, given the neurodevelopmental hypothesis for their pathogenesis. For example, it is speculated that reduced Vrk2 levels might induce apoptosis $[112,114]$, thereby affecting normal neurodevelopment during the early stages of life. In fact, Yu et al. [48] recently explored the potential functions of Vrk2 in developing mouse brains. They reported that Vrk2 was expressed in the developing cerebral cortex, and the silencing of Vrk2 resulted in the impairment of multipolar-bipolar neuron transition and neural progenitor proliferation [48]. Therefore, Vrk2 likely plays regulatory roles in cytoskeleton remodeling and progenitor cell recycling/differentiation [48].

While the exact mechanisms underlying the functions of Vrk2 in cell proliferation and survival are not fully understood, it is suggested that Vrk2 likely involves

VRK2 in Psychiatric and Neurological Disorders
JIP1 (Fig. 5), a crucial mediator of neurite initiation and axon outgrowth in neuronal cells $[115,116]$. Moreover, a previous study found that in the intracellular signaling pathways Vrk2 is also an upstream modulator of Erk1/ MAPK and CREB transcription factor [117], and activation of Vrk2 will affect MEK-induced gene transcription through reducing phosphorylation of key proteins in the relevant pathways (Fig. 5) $[115,118]$. Notably, both MAPK3 (encodes Erk1) $[13,119,120]$ and CREB1 [121, 122] are potentially involved in genetic susceptibility to SCZ, and CREB1 has also repeatedly been implicated in the genetic and molecular risk of BPD and MDD [123126]. In a recent study, Jeong et al. showed that Vrk2 directly interacts with dysbindin [113], a protein encoded by the important SCZ susceptibility gene DTNBP1 [127-130]. Vrk2 could phosphorylate dysbindin, which will consequently enhance its ubiquitination and decrease protein stability [113]. Moreover, Hirata et al. [131] found that Vrk2 interacts with Akt in the lysosomes, and the lysosomal Vrk2-Akt complex controls cellular proliferation and mitochondrial outer-membrane stabilization in the process of autophagy. Intriguingly, $A K T 1$ is also one of the best candidate genes for SCZ [132-137]. Since the susceptibility genes/proteins of psychiatric disorders usually form a highly interconnected protein-protein interaction network and are enriched in specific pathways involved in brain function and neurodevelopment [138-140], these data collectively provide essential hints for the biological mechanisms underlying the genetic susceptibility to psychiatric disorders conferred by VRK2.

In addition to its pivotal roles in cell proliferation and neurodevelopment, $V R K 2$ has been shown to participate in major posttranslational processes such as protein ubiquitination that could affect neurodegenerative disorders. For instance, Kim et al. [141] revealed that Vrk2 controlled the stability of the eukaryotic chaperonin TRiC (TCP-1 Ring Complex - also known as CCT, for chaperonin containing TCP-1) by inhibiting the deubiquitinating enzyme USP25, and Vrk2 could mediate accumulation of polyglutamine aggregates via negative regulation of TRiC [142]. Recently, Lee et al. [143] further showed that GSK3 $\beta$ directly bound to Vrk2, resulting in inhibition of Vrk2 catalytic activity, reduction of ubiquitination-proteosomal degradation of TRiC, and suppression of polyglutamine protein aggregation (Fig. 5). While these data suggest a potential involvement of Vrk2 in the development of neurodegenerative disorders, it remains an interesting topic for future investigations whether these pathways contribute to the 
pathogenesis of major psychiatric disorders (e.g., SCZ), given that GSK3 $\beta$ is likely a psychiatric susceptibility gene [144-156].

Another intriguing finding regarding Vrk2 function is the discovery of its role in inflammatory responses. In fact, this protein has been recognized for its involvement in the viral infection processes $[157,158]$. It has long been hypothesized that brain inflammation contributes to pathological alterations in SCZ, and a recent study indicates that $\mathrm{Vrk} 2$ can reduce the transcriptional response to interleukin-1b (IL-1b, encoded by $I L-1 B$ ) [115], a cytokine involved in inflammatory activity and psychiatric disorders [159-161]. Therefore, it also remains to be elucidated whether Vrk2 affects the major psychiatric disorders via IL-1b-related pathways. Additionally, in line with the inflammatory hypothesis for psychiatric disorders, researchers have studied proteins encoded by genes highlighted in previous GWAS studies to determine whether they could elicit autoantibody production, and thus be involved in inflammatory processes in the brain [162]. They found that Vrk2 was expressed by both neurons and B lymphocytes, and the serum levels of autoantibody against Vrk2 were significantly lower in SCZ patients compared with healthy subjects, suggesting a protective effect of the IgG against Vrk2 [162]. However, the exact mechanisms explaining this observation remain unclear. More interestingly, the administration of antipsychotic risperidone, whose anti-inflammatory effects have been previously described, could increase the level of $\operatorname{IgG}$ against Vrk2 [162]. While these findings need further replication, they strongly suggest the correlation between Vrk2 and brain inflammation in SCZ.

\section{Implications for Overlapped Genetic and Biological Basis of SCZ and MDD}

The discovery of VRK2 in genetic studies of SCZ and MDD adds convincing support for the shared genetic susceptibility factors between these two psychiatric disorders [11,163-166]. Although this hypothesis has long been raised based on the discoveries of susceptibility loci for both SCZ and major mood disorders [164, 167-169], the number of risk genes known to transcend the diagnostic categories remains limited. It is therefore intriguing to see that the same allele in VRK2 showed genomewide significant associations with both SCZ and MDD. These results not only indicate that VRK2 is a common risk gene in psychiatric disorders but also suggest that VRK2 may be involved in the shared biological pathways or intermediate phenotypes underlying both illnesses. It should also be noted that debates remain over the boundaries between the clinical symptoms and the degree to which they delineate distinct diagnostic categories of psychiatric disorders $[4,164,170-173]$. Systematic variations introduced by different researchers in sample recruitment during GWAS analyses or other genetic studies are therefore inevitable. This phenomenon, on the other hand, highlights the importance of further elucidation of the genetic and biological basis underlying the shared susceptibility components between psychiatric disorders, and future studies identifying the loci conferring risk of more specific symptoms may provide valuable insights for refining classifications of psychiatric conditions.

\section{Future Perspectives}

It is clear that VRK2 is of considerable interest, given its function in physiological processes as well as its association with major psychiatric and neurological diseases. While current knowledge of this gene and its protein product is relatively rudimentary, there are many unexplored questions that arise from these exciting findings. First, the effects of variants in VRK2 on the genetic risk of psychiatric disorders are considered to be only modest (odds ratio $\sim 1.10$ ) $[13-15,29]$, and the functions of the risk variants are still unclear. It is therefore under debate whether VRK2 could be directly used as a possible target in the future clinical management of these disorders. The detailed genetic mechanisms for its role in such disorders will provide essential information. In addition, studies describing the effects of $V R K 2$ on neurodevelopment and brain function are still lacking. Although there is preliminary evidence that this gene may affect neuronal migration [48] and inflammation $[115,159,160]$, whether it could affect other aspects of neuronal function, e.g. synaptic development and transmission, is still unclear. Furthermore, several studies have reported that proteins interact with Vrk2 or regulate its function $[143,174]$. Whether these mechanisms facilitate the pathogenesis of certain psychiatric and neurological disorders should be examined to reveal potential therapeutic opportunities.

In summary, in the present review, we have outlined the compelling evidence suggesting that VRK2 is a significant factor in the onset or/and development of SCZ and MDD. To the best of our knowledge, VRK2 is also one of the few genes showing genome-wide significant 
associations with both SCZ and MDD, making it an important subject for studies in the field of psychiatric genetics. Moreover, we have discussed the urgent need for further exploration of its role in the genetic architecture of psychiatric disorders (especially SCZ and MDD), the biological impact on neurodevelopment and brain function, and the roles of associated molecules in diseases. As the majority of studies on VRK2 were conducted in vitro, future utilization of animal- and/or human-derived tissues may provide valuable insights and information.

\section{Acknowledgement}

The authors would like to express regret to those authors whose work was not mentioned or elaborately represented in this review because of our ignorance and negligence during the literature survey. This study was supported by the National Natural Science Foundation of China (grant No. 81722019 to M.L.). M.L. was also supported by CAS Pioneer Hundred Talents Program and the 1000 Young Talents Program.

\section{Disclosure Statement}

All authors report no conflicts of interest.

\section{References}

1 van Os J, Kapur S. Schizophrenia. Lancet. 2009 Aug;374(9690):635-45.

2 Freedman R. Schizophrenia. N Engl J Med. 2003 Oct;349(18):1738-49.

3 McGrath J, Saha S, Chant D, Welham J. Schizophrenia: a concise overview of incidence, prevalence, and mortality. Epidemiol Rev. 2008;30(1):67-76.

4 Sullivan PF, Daly MJ, O'Donovan M. Genetic architectures of psychiatric disorders: the emerging picture and its implications. Nat Rev Genet. 2012 Jul;13(8):537-51.

5 DeLisi LE. A Case for Returning to Multiplex Families for Further Understanding the Heritability of Schizophrenia: A Psychiatrist's Perspective. Mol Neuropsychiatry. 2016 May; 2(1):15-9.

6 Sullivan PF, Kendler KS, Neale MC. Schizophrenia as a complex trait: evidence from a meta-analysis of twin studies. Arch Gen Psychiatry. 2003 Dec;60(12):1187-92.

7 Kupfer DJ, Frank E, Phillips ML. Major depressive disorder: new clinical, neurobiological, and treatment perspectives. Lancet. 2012 Mar;379(9820):1045-55.

8 Kessler RC, Berglund P, Demler O, Jin R, Koretz D, Merikangas KR, et al.; National Comorbidity Survey Replication. The epidemiology of major depressive disorder: results from the National Comorbidity Survey Replication (NCS-R). JAMA. 2003 Jun;289(23): 3095-105.

9 Belmaker RH, Agam G. Major depressive disorder. N Engl J Med. 2008 Jan;358(1):55-68.

10 Sullivan PF, Neale MC, Kendler KS. Genetic epidemiology of major depression: review and meta-analysis. Am J Psychiatry. 2000 Oct; 157(10):1552-62.

11 Ding Y, Chang LC, Wang X, Guilloux JP, Parrish J, Oh $\mathrm{H}$, et al. Molecular and Genetic Characterization of Depression: Overlap with other Psychiatric Disorders and Aging. Mol Neuropsychiatry. 2015 May;1(1):1-12.
12 Bigdeli TB, Ripke S, Peterson RE, Trzaskowski M, Bacanu SA, Abdellaoui A, et al. Genetic effects influencing risk for major depressive disorder in China and Europe. Transl Psychiatry. 2017 Mar;7(3):e1074.

13 Schizophrenia Working Group of the Psychiatric Genomics Consortium. Biological insights from 108 schizophrenia-associated genetic loci. Nature. 2014 Jul;511(7510):421-7.

14 Hyde CL, Nagle MW, Tian C, Chen X, Paciga SA, Wendland JR, et al. Identification of 15 genetic loci associated with risk of major depression in individuals of European descent. Nat Genet. 2016 Sep;48(9):1031-6.

15 Li Z, Chen J, Yu H, He L, Xu Y, Zhang D, et al. Genome-wide association analysis identifies 30 new susceptibility loci for schizophrenia. Nat Genet. 2017 Nov;49(11):1576-83.

16 Pardiñas AF, Holmans P, Pocklington AJ, Escott-Price V, Ripke S, Carrera N, et al.; GERAD1 Consortium; CRESTAR Consortium; GERAD1 Consortium; CRESTAR Consortium; GERAD1 Consortium; CRESTAR Consortium. Common schizophrenia alleles are enriched in mutation-intolerant genes and in regions under strong background selection. Nat Genet. 2018 Mar;50(3):381-9.

17 Ripke S, O'Dushlaine C, Chambert K, Moran JL, Kähler AK, Akterin S, et al.; Multicenter Genetic Studies of Schizophrenia Consortium; Psychosis Endophenotypes International Consortium; Wellcome Trust Case Control Consortium 2. Genome-wide association analysis identifies 13 new risk loci for schizophrenia. Nat Genet. 2013 Oct;45(10): 1150-9.

18 Yue WH, Wang HF, Sun LD, Tang FL, Liu $\mathrm{ZH}$, Zhang HX, et al. Genome-wide association study identifies a susceptibility locus for schizophrenia in Han Chinese at 11p11.2. Nat Genet. 2011 Oct;43(12):1228-31.

19 Cai N, Bigdeli TB, Kretzschmar W, Li Y, Liang J, Song L, et al.; CONVERGE consortium. Sparse whole-genome sequencing identifies two loci for major depressive disorder. Nature. 2015 Jul;523(7562):588-91.
20 Wray NR, Ripke S, Mattheisen M, Trzaskowski M, Byrne EM, Abdellaoui A, et al.; eQTLGen; 23andMe; Major Depressive Disorder Working Group of the Psychiatric Genomics Consortium. Genome-wide association analyses identify 44 risk variants and refine the genetic architecture of major depression. Nat Genet. 2018 May;50(5):668-81.

21 Avramopoulos D. Recent Advances in the Genetics of Schizophrenia. Mol Neuropsychiatry. 2018 Jun;4(1):35-51.

22 Visscher PM, Wray NR, Zhang Q, Sklar P, McCarthy MI, Brown MA, et al. 10 Years of GWAS Discovery: Biology, Function, and Translation. Am J Hum Genet. 2017 Jul; 101(1):5-22.

23 Rautiainen MR, Paunio T, Repo-Tiihonen E, Virkkunen M, Ollila HM, Sulkava S, et al. Genome-wide association study of antisocial personality disorder. Transl Psychiatry. 2016 Sep;6(9):e883.

24 Witt SH, Streit F, Jungkunz M, Frank J, Awasthi S, Reinbold CS, et al.; Bipolar Disorders Working Group of the Psychiatric Genomics Consortium; Major Depressive Disorder Working Group of the Psychiatric Genomics Consortium; Schizophrenia Working Group of the Psychiatric Genomics Consortium. Genome-wide association study of borderline personality disorder reveals genetic overlap with bipolar disorder, major depression and schizophrenia. Transl Psychiatry. 2017 Jun; 7(6):e1155.

25 Xiao X, Wang L, Wang C, Yuan TF, Zhou D, Zheng F, et al.; Advanced Collaborative Study of Mood Disorder (COSMO) Team, MooDS Bipolar Consortium. Common variants at $2 \mathrm{q} 11.2,8 \mathrm{q} 21.3$, and $11 \mathrm{q} 13.2$ are associated with major mood disorders. Transl Psychiatry. 2017 Dec;7(12):1273.

26 Penzes P, Cahill ME, Jones KA, VanLeeuwen JE, Woolfrey KM. Dendritic spine pathology in neuropsychiatric disorders. Nat Neurosci. 2011 Mar;14(3):285-93. 
27 Forrest MP, Parnell E, Penzes P. Dendritic structural plasticity and neuropsychiatric disease. Nat Rev Neurosci. 2018 Mar;19(4):21534.

28 Stefansson H, Ophoff RA, Steinberg S, Andreassen OA, Cichon S, Rujescu D, et al.; Genetic Risk and Outcome in Psychosis (GROUP). Common variants conferring risk of schizophrenia. Nature. 2009 Aug;460(7256):744-7.

29 Steinberg S, de Jong S, Andreassen OA, Werge $\mathrm{T}$, Børglum AD, Mors O, et al.; Irish Schizophrenia Genomics Consortium; GROUP; Wellcome Trust Case Control Consortium 2. Common variants at VRK2 and TCF4 conferring risk of schizophrenia. Hum Mol Genet. 2011 Oct;20(20):4076-81.

30 Irish Schizophrenia Genomics Consortium and the Wellcome Trust Case Control Consortium 2. Genome-wide association study implicates HLA-C*01:02 as a risk factor at the major histocompatibility complex locus in schizophrenia. Biol Psychiatry. 2012 Oct; 72(8):620-8.

31 Zhang B, Gao CY, Zhang HB, Yang B, Yin JF, Wei SG, et al. Association of the VRK2 gene rs3732136 polymorphism with schizophrenia in a Northwest Chinese Han population. Genet Mol Res. 2015 Aug;14(3):9404-11.

32 Bocharova AV, Stepanov VA, Marusin AV, Kharkov VN, Vagaitseva KV, Fedorenko OY, et al. [Association study of genetic markers of schizophrenia and its cognitive endophenotypes]. Genetika. 2017 Jan;53(1):100-8.

33 Stepanov VA, Bocharova AV, Saduakassova KZ, Marusin AV, Koneva LA, Vagaitseva KV, et al. [Replicative study of susceptibility to childhood-onset schizophrenia in Kazakhs]. Genetika. 2015 Feb;51(2):227-35.

34 Li M, Wang Y, Zheng XB, Ikeda M, Iwata N, Luo XJ, et al.; MooDS Consortium. Metaanalysis and brain imaging data support the involvement of VRK2 (rs2312147) in schizophrenia susceptibility. Schizophr Res. 2012 Dec;142(1-3):200-5.

35 Xiao X, Luo XJ, Chang H, Liu Z, Li M. Evaluation of European Schizophrenia GWAS Loci in Asian Populations via Comprehensive Meta-Analyses. Mol Neurobiol. 2017 Aug;54(6): 4071-80.

36 Chang H, Zhang C, Xiao X, Pu X, Liu Z, Wu L, et al. Further evidence of VRK2 rs2312147 associated with schizophrenia. World J Biol Psychiatry. 2016 Sep;17(6):457-66.

37 Pickrell JK, Coop G, Novembre J, Kudaravalli S, Li JZ, Absher D, et al. Signals of recent positive selection in a worldwide sample of human populations. Genome Res. 2009 May; 19(5):826-37.

38 Pritchard JK, Pickrell JK, Coop G. The genetics of human adaptation: hard sweeps, soft sweeps, and polygenic adaptation. Curr Biol. 2010 Feb;20(4):R208-15

39 Coop G, Pickrell JK, Novembre J, Kudaravalli S, Li J, Absher D, et al. The role of geography in human adaptation. PLoS Genet. 2009 Jun; 5(6):e1000500.
40 Edwards SL, Beesley J, French JD, Dunning AM. Beyond GWASs: illuminating the dark road from association to function. Am J Hum Genet. 2013 Nov;93(5):779-97.

41 Sekar A, Bialas AR, de Rivera H, Davis A, Hammond TR, Kamitaki N, et al.; Schizophrenia Working Group of the Psychiatric Genomics Consortium. Schizophrenia risk from complex variation of complement component 4. Nature. 2016 Feb;530(7589):17783.

42 Li M, Jaffe AE, Straub RE, Tao R, Shin JH, Wang Y, et al. A human-specific AS3MT isoform and BORCS7 are molecular risk factors in the 10q24.32 schizophrenia-associated locus. Nat Med. 2016 Jun;22(6):649-56.

43 Bray NJ, Hill MJ. Translating Genetic Risk Loci Into Molecular Risk Mechanisms for Schizophrenia. Schizophr Bull. 2016 Jan; 42(1):5-8

44 Lonsdale J, Thomas J, Salvatore M, Phillips R, Lo E, Shad S, et al.; GTEx Consortium. The Genotype-Tissue Expression (GTEx) project. Nat Genet. 2013 Jun;45(6):580-5.

45 Ramasamy A, Trabzuni D, Guelfi S, Varghese V, Smith C, Walker R, et al.; UK Brain Expression Consortium; North American Brain Expression Consortium. Genetic variability in the regulation of gene expression in ten regions of the human brain. Nat Neurosci. 2014 Oct;17(10):1418-28.

46 Colantuoni C, Lipska BK, Ye T, Hyde TM, Tao R, Leek JT, et al. Temporal dynamics and genetic control of transcription in the human prefrontal cortex. Nature. 2011 Oct; 478(7370):519-23.

47 ENCODE Project Consortium. An integrated encyclopedia of DNA elements in the human genome. Nature. 2012 Sep;489(7414):57-74.

48 Yu H, Yan H, Li J, Li Z, Zhang X, Ma Y, et al.; Chinese Schizophrenia Collaboration Group. Common variants on $2 \mathrm{p} 16.1,6 \mathrm{p} 22.1$ and $10 \mathrm{q} 24.32$ are associated with schizophrenia in Han Chinese population. Mol Psychiatry. 2017 Jul;22(7):954-60.

49 Stahl E, Forstner A, McQuillin A, Ripke S, Ophoff R, Scott L, et al. Genomewide association study identifies 30 loci associated with bipolar disorder. bioRxiv. 2017;173062.

50 Weinberger DR. Implications of normal brain development for the pathogenesis of schizophrenia. Arch Gen Psychiatry. 1987 Jul; 44(7):660-9.

51 Breier A, Buchanan RW, Elkashef A, Munson RC, Kirkpatrick B, Gellad F. Brain morphology and schizophrenia. A magnetic resonance imaging study of limbic, prefrontal cortex, and caudate structures. Arch Gen Psychiatry. 1992 Dec;49(12):921-6.

52 Birnbaum R, Weinberger DR. Genetic insights into the neurodevelopmental origins of schizophrenia. Nat Rev Neurosci. 2017 Dec; 18(12):727-40

53 Weinberger DR. The neurodevelopmental origins of schizophrenia in the penumbra of genomic medicine. World Psychiatry. 2017 Oct;16(3):225-6.
54 Saia-Cereda VM, Santana AG, Schmitt A, Falkai P, Martins-de-Souza D. The Nuclear Proteome of White and Gray Matter from Schizophrenia Postmortem Brains. Mol Neuropsychiatry. 2017 Jul;3(1):37-52.

55 Chen Z, Peng W, Sun H, Kuang W, Li W, Jia $Z$, et al. High-field magnetic resonance imaging of structural alterations in first-episode, drug-naive patients with major depressive disorder. Transl Psychiatry. 2016 Nov;6(11): e942.

56 Henje Blom E, Han LK, Connolly CG, Ho TC Lin J, LeWinn KZ, et al. Peripheral telomere length and hippocampal volume in adolescents with major depressive disorder. Transl Psychiatry. 2015 Nov;5(11):e676.

57 Rentería ME, Schmaal L, Hibar DP, CouvyDuchesne B, Strike LT, Mills NT, et al. Subcortical brain structure and suicidal behaviour in major depressive disorder: a metaanalysis from the ENIGMA-MDD working group. Transl Psychiatry. 2017 May;7(5): e1116.

58 Schmaal L, Hibar DP, Sämann PG, Hall GB, Baune BT, Jahanshad N, et al. Cortical abnormalities in adults and adolescents with major depression based on brain scans from $20 \mathrm{co}-$ horts worldwide in the ENIGMA Major Depressive Disorder Working Group. Mol Psychiatry. 2017 Jun;22(6):900-9.

59 Schmaal L, Veltman DJ, van Erp TG, Sämann PG, Frodl T, Jahanshad N, et al. Subcortical brain alterations in major depressive disorder: findings from the ENIGMA Major Depressive Disorder working group. Mol Psychiatry. 2016 Jun;21(6):806-12.

60 Meyer-Lindenberg A, Weinberger DR. Intermediate phenotypes and genetic mechanisms of psychiatric disorders. Nat Rev Neurosci. 2006 Oct;7(10):818-27.

61 Hasler G, Northoff G. Discovering imaging endophenotypes for major depression. Mol Psychiatry. 2011 Jun;16(6):604-19.

62 Hasler G, Drevets WC, Manji HK, Charney DS. Discovering endophenotypes for major depression. Neuropsychopharmacology. 2004 Oct;29(10):1765-81.

63 Leuchter AF, Hunter AM, Krantz DE, Cook IA. Intermediate phenotypes and biomarkers of treatment outcome in major depressive disorder. Dialogues Clin Neurosci. 2014 Dec; 16(4):525-37.

64 Wedenoja J, Tuulio-Henriksson A, Suvisaari J, Loukola A, Paunio T, Partonen T, et al. Replication of association between working memory and Reelin, a potential modifier gene in schizophrenia. Biol Psychiatry. 2010 May; 67(10):983-91.

65 Wedenoja J, Loukola A, Tuulio-Henriksson A, Paunio T, Ekelund J, Silander K, et al. Replication of linkage on chromosome 7q22 and association of the regional Reelin gene with working memory in schizophrenia families. Mol Psychiatry. 2008 Jul;13(7):673-84. 
66 Rasetti R, Sambataro F, Chen Q, Callicott JH, Mattay VS, Weinberger DR. Altered cortical network dynamics: a potential intermediate phenotype for schizophrenia and association with ZNF804A. Arch Gen Psychiatry. 2011 Dec;68(12):1207-17.

67 Walter H, Schnell K, Erk S, Arnold C, Kirsch $\mathrm{P}$, Esslinger C, et al. Effects of a genome-wide supported psychosis risk variant on neural activation during a theory-of-mind task. Mol Psychiatry. 2011 Apr;16(4):462-70.

68 Walters JT, Corvin A, Owen MJ, Williams H, Dragovic M, Quinn EM, et al. Psychosis susceptibility gene ZNF804A and cognitive performance in schizophrenia. Arch Gen Psychiatry. $2010 \mathrm{Jul} ; 67(7): 692-700$.

69 Bigos KL, Mattay VS, Callicott JH, Straub RE, Vakkalanka R, Kolachana B, et al. Genetic variation in CACNA1C affects brain circuitries related to mental illness. Arch Gen Psychiatry. 2010 Sep;67(9):939-45.

70 Erk S, Meyer-Lindenberg A, Schnell K, Opitz von Boberfeld C, Esslinger C, Kirsch P, et al. Brain function in carriers of a genome-wide supported bipolar disorder variant. Arch Gen Psychiatry. 2010 Aug;67(8):803-11.

71 Radua J, Surguladze SA, Marshall N, Walshe M, Bramon E, Collier DA, et al. The impact of CACNA1C allelic variation on effective connectivity during emotional processing in bipolar disorder. Mol Psychiatry. 2013 May; 18(5):526-7.

72 Soeiro-de-Souza MG, Lafer B, Moreno RA, Nery FG, Chile T, Chaim K, et al. The CACNA1C risk allele rs 1006737 is associated with age-related prefrontal cortical thinning in bipolar I disorder. Transl Psychiatry. 2017 Apr; 7(4):e1086.

73 Oestreich LK, Lyall AE, Pasternak O, Kikinis Z, Newell DT, Savadjiev P, et al. Australian Schizophrenia Research B, Whitford TJ, McCarthy-Jones S: Characterizing white matter changes in chronic schizophrenia: A free-water imaging multi-site study. Schizophr Res. 2017;189:153-61

74 Sohn H, Kim B, Kim KH, Kim MK, Choi TK, Lee SH. Effects of VRK2 (rs2312147) on white matter connectivity in patients with schizophrenia. PLoS One. 2014 Jul;9(7):e103519.

75 Epicure Consortium, EMINet Consortium. Steffens M, Leu C, Ruppert AK, Zara F, Striano P, Robbiano A, et al.: Genome-wide association analysis of genetic generalized epilepsies implicates susceptibility loci at $1 \mathrm{q} 43$, 2p16.1, 2q22.3 and 17q21.32. Hum Mol Genet. 2012;21:5359-72.

76 Jallon P, Loiseau P, Loiseau J. Newly diagnosed unprovoked epileptic seizures: presentation at diagnosis in CAROLE study. Coordination Active du Réseau Observatoire Longitudinal de l' Epilepsie. Epilepsia. 2001 Apr; 42(4):464-75.

77 International League Against Epilepsy Consortium on Complex Epilepsies. Genetic determinants of common epilepsies: a metaanalysis of genome-wide association studies. Lancet Neurol. 2014 Sep;13(9):893-903.
78 Josephson CB, Jetté N. Psychiatric comorbidities in epilepsy. Int Rev Psychiatry. 2017 Oct; 29(5):409-24.

79 Wu Y, Yao YG, Luo XI. SZDB: A Database for Schizophrenia Genetic Research. Schizophr Bull. 2017 Mar;43(2):459-71.

80 Tesli M, Wirgenes KV, Hughes T, Bettella F, Athanasiu L, Hoseth ES, et al. VRK2 gene expression in schizophrenia, bipolar disorder and healthy controls. Br J Psychiatry. 2016 Aug;209(2):114-20.

81 Azimi T, Ghafouri-Fard S, Davood Omrani M, Mazdeh M, Arsang-Jang S, Sayad A, et al. Vaccinia Related Kinase 2 (VRK2) expression in neurological disorders: schizophrenia, epilepsy and multiple sclerosis. Mult Scler Relat Disord. 2018 Jan;19:15-9.

82 Kim S, Webster MJ. The stanley neuropathology consortium integrative database: a novel, web-based tool for exploring neuropathological markers in psychiatric disorders and the biological processes associated with abnormalities of those markers. Neuropsychopharmacology. 2010 Jan;35(2):473-82.

83 Cao Y, Zhu J, Jia P, Zhao Z. scRNASeqDB: A Database for RNA-Seq Based Gene Expression Profiles in Human Single Cells. Genes (Basel). 2017 Dec;8(12):8.

84 Darmanis S, Sloan SA, Zhang Y, Enge M, Caneda C, Shuer LM, et al. A survey of human brain transcriptome diversity at the single cell level. Proc Natl Acad Sci USA. 2015 Jun; 112(23):7285-90.

85 Bouras N. Psychiatric and behavioural disorders in developmental disabilities and mental retardation. Cambridge: Cambridge University Press; 1999.

86 Borthwick-Duffy SA. Epidemiology and prevalence of psychopathology in people with mental retardation. J Consult Clin Psychol. $1994 \mathrm{Feb} ; 62(1): 17-27$.

87 Steffenburg S, Gillberg C, Steffenburg U. Psychiatric disorders in children and adolescents with mental retardation and active epilepsy. Arch Neurol. 1996 Sep;53(9):904-12.

88 Strømme P, Diseth TH. Prevalence of psychiatric diagnoses in children with mental retardation: data from a population-based study. Dev Med Child Neurol. 2000 Apr;42(4):26670.

89 Emerson E. Prevalence of psychiatric disorders in children and adolescents with and without intellectual disability. I Intellect Disabil Res. 2003 Jan;47(Pt 1):51-8.

90 Walsh T, McClellan JM, McCarthy SE, Addington AM, Pierce SB, Cooper GM, et al. Rare structural variants disrupt multiple genes in neurodevelopmental pathways in schizophrenia. Science. 2008 Apr;320(5875):53943.

91 Belmonte MK, Allen G, Beckel-Mitchener A, Boulanger LM, Carper RA, Webb SJ. Autism and abnormal development of brain connectivity. J Neurosci. 2004 Oct;24(42):9228-31.

92 Courchesne E. Abnormal early brain development in autism. Mol Psychiatry. 2002;7(S2 Suppl 2):S21-3.
93 Hankin BL, Oppenheimer C, Jenness J, Barrocas A, Shapero BG, Goldband J. Developmental origins of cognitive vulnerabilities to depression: review of processes contributing to stability and change across time. J Clin Psychol. 2009 Dec;65(12):1327-38.

94 Ansorge MS, Hen R, Gingrich JA. Neurodevelopmental origins of depressive disorders. Curr Opin Pharmacol. 2007 Feb;7(1):8-17.

95 Geoffroy PA, Etain B, Scott J, Henry C, Jamain S, Leboyer M, et al. Reconsideration of bipolar disorder as a developmental disorder: importance of the time of onset. J Physiol Paris. 2013 Sep;107(4):278-85.

96 Mochida GH, Walsh CA. Molecular genetics of human microcephaly. Curr Opin Neurol. 2001 Apr;14(2):151-6.

97 Lancaster MA, Renner M, Martin CA, Wenzel D, Bicknell LS, Hurles ME, et al. Cerebral organoids model human brain development and microcephaly. Nature. 2013 Sep; 501(7467):373-9.

98 Shevell M. Global developmental delay and mental retardation or intellectual disability: conceptualization, evaluation, and etiology [xi.]. Pediatr Clin North Am. 2008 Oct; 55(5):1071-84

99 Chandler KE, Del Rio A, Rakshi K, Springell K, Williams DK, Stoodley N, et al. Leucodysplasia, microcephaly, cerebral malformation (LMC): a novel recessive disorder linked to 2p16. Brain. 2006 Jan;129(Pt 1):272-7.

100 Rajcan-Separovic E, Harvard C, Liu X, McGillivray B, Hall JG, Qiao Y, et al. Clinical and molecular cytogenetic characterisation of a newly recognised microdeletion syndrome involving 2p15-16.1. J Med Genet. 2007 Apr;44(4):269-76.

101 de Leeuw N, Pfundt R, Koolen DA, Neefs I, Scheltinga I, Mieloo H, et al. A newly recognised microdeletion syndrome involving 2 p15p16.1: narrowing down the critical region by adding another patient detected by genome wide tiling path array comparative genomic hybridisation analysis. J Med Genet. $2008 \mathrm{Feb} ; 45(2): 122-4$

102 Gregory AM, O'Connor TG. Sleep problems in childhood: a longitudinal study of developmental change and association with behavioral problems. J Am Acad Child Adolesc Psychiatry. 2002 Aug;41(8):964-71.

103 Jones SE, Tyrrell J, Wood AR, Beaumont RN, Ruth KS, Tuke MA, et al. Genome-Wide Association Analyses in 128,266 Individuals Identifies New Morningness and Sleep Duration Loci. PLoS Genet. 2016 Aug;12(8): e1006125.

104 Sanz-Garcia M, Valbuena A, López-Sánchez I, Blanco S, Fernández I, Vázquez-Cedeira M, Lazo P: Vaccinia-related kinase (VRK) signaling in cell and tumor biology. Emerg Signal Pathways Tumor Biol 2010:135-56.

105 Klerkx EP, Lazo PA, Askjaer P. Emerging biological functions of the vaccinia-related kinase (VRK) family. Histol Histopathol. 2009 Jun;24(6):749-59. 
106 Nezu J, Oku A, Jones MH, Shimane M. Identification of two novel human putative serine/threonine kinases, VRK1 and VRK2, with structural similarity to vaccinia virus B1R kinase. Genomics. 1997 Oct;45(2):32731.

107 Blanco S, Klimcakova L, Vega FM, Lazo PA. The subcellular localization of vaccinia-related kinase-2 (VRK2) isoforms determines their different effect on p53 stability in tumour cell lines. FEBS J. 2006 Jun;273(11): 2487-504.

108 Birendra Kc, May DG, Benson BV, Kim DI, Shivega WG, Ali MH, et al. VRK2A is an Atype lamin-dependent nuclear envelope kinase that phosphorylates BAF. Mol Biol Cell. 2017 Aug;28(17):2241-50.

109 Vega FM, Gonzalo P, Gaspar ML, Lazo PA. Expression of the VRK (vaccinia-related kinase) gene family of p53 regulators in murine hematopoietic development. FEBS Lett. 2003 Jun;544(1-3):176-80.

110 Rodríguez-Hernández I, Vázquez-Cedeira M, Santos-Briz A, García JL, Fernández IF, Gómez-Moreta JA, et al. VRK2 identifies a subgroup of primary high-grade astrocytomas with a better prognosis. BMC Clin Pathol. 2013 Oct;13(1):23.

111 Del Puerto-Nevado L, Marin-Arango JP, Fernandez-Aceñero MJ, Arroyo-Manzano D, Martinez-Useros J, Borrero-Palacios A, et al. Predictive value of vrk 1 and 2 for rectal adenocarcinoma response to neoadjuvant chemoradiation therapy: a retrospective observational cohort study. BMC Cancer. 2016 Jul;16(1):519.

112 Li LY, Liu MY, Shih HM, Tsai CH, Chen JY. Human cellular protein VRK2 interacts specifically with Epstein-Barr virus BHRF1, a homologue of $\mathrm{Bcl}-2$, and enhances cell survival. J Gen Virol. 2006 Oct;87(Pt 10):286978.

113 Jeong YH, Choi JH, Lee D, Kim S, Kim KT. Vaccinia-related kinase 2 modulates role of dysbindin by regulating protein stability. J Neurochem. 2018 Jul. https://doi.org/ 10.1111/jnc. 14562.

114 Monsalve DM, Merced T, Fernández IF, Blanco S, Vázquez-Cedeira M, Lazo PA. Human VRK2 modulates apoptosis by interaction with $\mathrm{Bcl}-\mathrm{xL}$ and regulation of $\mathrm{BAX}$ gene expression. Cell Death Dis. 2013 Feb; 4(2):e513.

115 Blanco S, Sanz-García M, Santos CR, Lazo PA. Modulation of interleukin-1 transcriptional response by the interaction between VRK2 and the JIP1 scaffold protein. PLoS One. 2008 Feb;3(2):e1660.

116 Dajas-Bailador F, Jones EV, Whitmarsh AJ. The JIP1 scaffold protein regulates axonal development in cortical neurons. Curr Biol. 2008 Feb;18(3):221-6.

117 Fernández IF, Pérez-Rivas LG, Blanco S, Castillo-Dominguez AA, Lozano J, Lazo PA. VRK2 anchors KSR1-MEK1 to endoplasmic reticulum forming a macromolecular complex that compartmentalizes MAPK signal- ing. Cell Mol Life Sci. 2012 Nov;69(22): 3881-93.

118 Blanco S, Santos C, Lazo PA. Vaccinia-related kinase 2 modulates the stress response to hypoxia mediated by TAK1. Mol Cell Biol. 2007 Oct;27(20):7273-83.

119 Blizinsky KD, Diaz-Castro B, Forrest MP, Schürmann B, Bach AP, Martin-de-Saavedra MD, et al. Reversal of dendritic phenotypes in 16p11.2 microduplication mouse model neurons by pharmacological targeting of a network hub. Proc Natl Acad Sci USA. 2016 Jul;113(30):8520-5.

120 Chang H, Li L, Li M, Xiao X. Rare and common variants at $16 \mathrm{p} 11.2$ are associated with schizophrenia. Schizophr Res. 2017 Jun;184: 105-8.

121 Crisafulli C, Chiesa A, Han C, Lee SJ, Shim DS, Balzarro B, et al. Possible influence of CREB1, CREBBP and CREM variants on diagnosis and treatment outcome in patients with schizophrenia. Neurosci Lett. 2012 Feb; 508(1):37-41.

122 Ma L, Wu DD, Ma SL, Tan L, Chen X, Tang NL, et al. Molecular evolution in the CREB1 signal pathway and a rare haplotype in CREB1 with genetic predisposition to schizophrenia. J Psychiatr Res. 2014 Oct;57: 84-9.

123 Li M, Luo XJ, Rietschel M, Lewis CM, Mattheisen M, Müller-Myhsok B, et al.; MooDS Bipolar Consortium; Swedish Bipolar Study Group; Alzheimer's Disease Neuroimaging Initiative; ENIGMA Consortium; CHARGE Consortium. Allelic differences between Europeans and Chinese for CREB1 SNPs and their implications in gene expression regulation, hippocampal structure and function, and bipolar disorder susceptibility. Mol Psychiatry. 2014 Apr;19(4):452-61.

124 Dong C, Wong ML, Licinio J. Sequence variations of ABCB1, SLC6A2, SLC6A3, SLC6A4, CREB1, CRHR1 and NTRK2: association with major depression and antidepressant response in Mexican-Americans. Mol Psychiatry. 2009 Dec;14(12):1105-18.

125 Hettema JM, An SS, van den Oord EJ, Neale MC, Kendler KS, Chen X. Association study of CREB1 with Major Depressive Disorder and related phenotypes. Am J Med Genet B Neuropsychiatr Genet. 2009 Dec;150B(8): 1128-32.

126 Xiao X, Zhang C, Grigoroiu-Serbanescu M, Wang L, Li L, Zhou D, et al. The cAMP responsive element-binding (CREB)-1 gene increases risk of major psychiatric disorders. Mol Psychiatry. 2017 Nov 21. doi: 10.1038/ mp.2017.243. [Epub ahead of print].

127 Straub RE, Jiang Y, MacLean CJ, Ma Y, Webb BT, Myakishev MV, et al. Genetic variation in the $6 \mathrm{p} 22.3$ gene DTNBP1, the human ortholog of the mouse dysbindin gene, is associated with schizophrenia. Am J Hum Genet. 2002 Aug;71(2):337-48.

128 Van Den Bogaert A, Schumacher J, Schulze TG, Otte AC, Ohlraun S, Kovalenko S, et al. The DTNBP1 (dysbindin) gene contributes to schizophrenia, depending on family history of the disease. Am J Hum Genet. 2003 Dec;73(6):1438-43.

129 Tang JX, Zhou J, Fan JB, Li XW, Shi YY, Gu NF, et al. Family-based association study of DTNBP1 in 6p22.3 and schizophrenia. Mol Psychiatry. 2003 Aug;8(8):717-8.

130 van den Oord EJ, Sullivan PF, Jiang Y, Walsh D, O'Neill FA, Kendler KS, et al. Identification of a high-risk haplotype for the dystrobrevin binding protein 1 (DTNBP1) gene in the Irish study of high-density schizophrenia families. Mol Psychiatry. 2003 May;8(5): 499-510.

131 Hirata N, Suizu F, Matsuda-Lennikov M, Tanaka T, Edamura T, Ishigaki S, et al. Functional characterization of lysosomal interaction of Akt with VRK2. Oncogene. 2018 Jun; 37(40):5367-86.

132 Nicodemus KK, Law AJ, Radulescu E, Luna A, Kolachana B, Vakkalanka R, et al. Biological validation of increased schizophrenia risk with NRG1, ERBB4, and AKT1 epistasis via functional neuroimaging in healthy controls. Arch Gen Psychiatry. 2010 Oct;67(10): 991-1001.

133 Ikeda M, Iwata N, Suzuki T, Kitajima T, Yamanouchi Y, Kinoshita Y, et al. Association of AKT1 with schizophrenia confirmed in a Japanese population. Biol Psychiatry. 2004 Nov;56(9):698-700.

134 Schwab SG, Hoefgen B, Hanses C, Hassenbach MB, Albus M, Lerer B, et al. Further evidence for association of variants in the AKT1 gene with schizophrenia in a sample of European sib-pair families. Biol Psychiatry. 2005 Sep;58(6):446-50.

135 Thiselton DL, Vladimirov VI, Kuo PH, McClay J, Wormley B, Fanous A, et al. AKT1 is associated with schizophrenia across multiple symptom dimensions in the Irish study of high density schizophrenia families. Biol Psychiatry. 2008 Mar;63(5):449-57.

136 Emamian ES, Hall D, Birnbaum MJ, Karayiorgou M, Gogos JA. Convergent evidence for impaired AKT1-GSK3beta signaling in schizophrenia. Nat Genet. 2004 Feb;36(2): 131-7.

137 Blasi G, Napolitano F, Ursini G, Taurisano P, Romano R, Caforio G, et al. DRD2/AKT1 interaction on D2 c-AMP independent signaling, attentional processing, and response to olanzapine treatment in schizophrenia. Proc Natl Acad Sci USA. 2011 Jan;108(3): 1158-63.

138 Luo X, Huang L, Jia P, Li M, Su B, Zhao Z, et al. Protein-protein interaction and pathway analyses of top schizophrenia genes reveal schizophrenia susceptibility genes converge on common molecular networks and enrichment of nucleosome (chromatin) assembly genes in schizophrenia susceptibility loci. Schizophr Bull. 2014 Jan;40(1):39-49.

139 Ma C, Gu C, Huo Y, Li X, Luo XJ. The integrated landscape of causal genes and pathways in schizophrenia. Transl Psychiatry. 2018 Mar;8(1):67. 
140 Network and Pathway Analysis Subgroup of Psychiatric Genomics Consortium. Psychiatric genome-wide association study analyses implicate neuronal, immune and histone pathways. Nat Neurosci. 2015 Feb;18(2): 199-209.

141 Kim S, Lee D, Lee J, Song H, Kim HJ, Kim KT. Vaccinia-Related Kinase 2 Controls the Stability of the Eukaryotic Chaperonin TRiC/CCT by Inhibiting the Deubiquitinating Enzyme USP25. Mol Cell Biol. 2015 May;35(10):1754-62.

142 Kim S, Park DY, Lee D, Kim W, Jeong YH, Lee J, et al. Vaccinia-related kinase 2 mediates accumulation of polyglutamine aggregates via negative regulation of the chaperonin TRiC. Mol Cell Biol. 2014 Feb;34(4): 643-52.

143 Lee E, Ryu HG, Kim S, Lee D, Jeong YH, Kim KT. Glycogen synthase kinase $3 \beta$ suppresses polyglutamine aggregation by inhibiting Vaccinia-related kinase 2 activity. Sci Rep. 2016 Jul;6(1):29097.

144 Li M, Mo Y, Luo XJ, Xiao X, Shi L, Peng YM, et al. Genetic association and identification of a functional SNP at GSK3 $\beta$ for schizophrenia susceptibility. Schizophr Res. 2011 Dec;133(1-3):165-71.

145 Blasi G, Napolitano F, Ursini G, Di Giorgio A, Caforio G, Taurisano P, et al. Association of GSK-3 $\beta$ genetic variation with GSK-3 $\beta$ expression, prefrontal cortical thickness, prefrontal physiology, and schizophrenia. Am J Psychiatry. 2013 Aug;170(8):868-76.

146 Inkster B, Nichols TE, Saemann PG, Auer DP, Holsboer F, Muglia P, et al. Association of GSK3beta polymorphisms with brain structural changes in major depressive disorder. Arch Gen Psychiatry. 2009 Jul;66(7):721-8.

147 Wang JR, Sun PH, Ren ZX, Meltzer HY, Zhen XC. GSK-3 $\beta$ Interacts with Dopamine D1 Receptor to Regulate Receptor Function: Implication for Prefrontal Cortical D1 Receptor Dysfunction in Schizophrenia. CNS Neurosci Ther. 2017 Feb;23(2):174-87.

148 Saus E, Soria V, Escaramís G, Crespo JM, Valero J, Gutiérrez-Zotes A, et al. A haplotype of glycogen synthase kinase $3 \beta$ is associated with early onset of unipolar major depression. Genes Brain Behav. 2010 Oct;9(7): 799-807.

149 Chen J, Wang M, Waheed Khan RA, He K, Wang Q, Li Z, et al. The GSK3B gene confers risk for both major depressive disorder and schizophrenia in the Han Chinese population. J Affect Disord. 2015 Oct; 185:149-55.

150 Zhang K, Yang C, Xu Y, Sun N, Yang H, Liu $\mathrm{J}$, et al. Genetic association of the interaction between the BDNF and GSK3B genes and major depressive disorder in a Chinese population. J Neural Transm (Vienna). 2010 Mar;117(3):393-401.

151 Liu S, Wang L, Sun N, Yang C, Liu Z, Li X, et al. The gender-specific association of rs334558 in GSK3 $\beta$ with major depressive disorder. Medicine (Baltimore). 2017 Jan; 96(3):e5928.
152 Tang H, Shen N, Jin H, Liu D, Miao X, Zhu LQ. GSK-3 $\beta$ polymorphism discriminates bipolar disorder and schizophrenia: a systematic meta-analysis. Mol Neurobiol. 2013 Dec;48(3):404-11.

153 Tamura M, Mukai J, Gordon JA, Gogos JA Developmental Inhibition of Gsk3 Rescues Behavioral and Neurophysiological Deficits in a Mouse Model of Schizophrenia Predisposition. Neuron. 2016 Mar;89(5):1100-9.

154 Xing B, Li YC, Gao WJ. GSK3 $\beta$ Hyperactivity during an Early Critical Period Impairs Prefrontal Synaptic Plasticity and Induces Lasting Deficits in Spine Morphology and Working Memory. Neuropsychopharmacology. 2016 Dec;41(13):3003-15.

$155 \mathrm{Hu}$ G, Yang C, Zhao L, Fan Y, Lv Q, Zhao J, et al. The interaction of NOS1AP, DISC1, DAOA, and GSK3B confers susceptibility of early-onset schizophrenia in Chinese Han population. Prog Neuropsychopharmacol Biol Psychiatry. 2018 Feb;81:187-93.

156 Liu Z, Guo H, Cao X, Cheng C, Yang C, Xu $\mathrm{C}$, et al. A combined study of GSK3 $\beta$ polymorphisms and brain network topological metrics in major depressive disorder. Psychiatry Res. 2014 Sep;223(3):210-7.

157 Suzuki Y, Ogawa K, Koyanagi Y, Suzuki Y. Functional disruption of the moloney murine leukemia virus preintegration complex by vaccinia-related kinases. $\mathrm{J}$ Biol Chem. $2010 \mathrm{Jul} ; 285(31): 24032-43$.

158 Olson AT, Rico AB, Wang Z, Delhon G, Wiebe MS. Deletion of the Vaccinia Virus B1 Kinase Reveals Essential Functions of This Enzyme Complemented Partly by the Homologous Cellular Kinase VRK2. J Virol. 2017 Jul;91(15):91.

159 Yu YW, Chen TJ, Hong CJ, Chen HM, Tsai SJ. Association study of the interleukin-1 beta $(\mathrm{C}-511 \mathrm{~T})$ genetic polymorphism with major depressive disorder, associated symptomatology, and antidepressant response. Neuropsychopharmacology. 2003 Jun; 28(6):1182-5.

160 Raison CL, Capuron L, Miller AH. Cytokines sing the blues: inflammation and the pathogenesis of depression. Trends Immunol. 2006 Jan;27(1):24-31.

161 Pace TW, Mletzko TC, Alagbe O, Musselman DL, Nemeroff CB, Miller AH, et al. Increased stress-induced inflammatory responses in male patients with major depression and increased early life stress. Am J Psychiatry. 2006 Sep;163(9):1630-3.

162 Whelan R, St Clair D, Mustard CJ, Hallford P, Wei J. Study of Novel Autoantibodies in Schizophrenia. Schizophr Bull. 2018 Oct; 44(6):1341-1349.

163 Huang J, Perlis RH, Lee PH, Rush AJ, Fava $\mathrm{M}$, Sachs GS, et al. Cross-disorder genomewide analysis of schizophrenia, bipolar disorder, and depression. Am J Psychiatry. 2010 Oct; 167(10):1254-63.

164 Cross-Disorder Group of the Psychiatric Genomics Consortium. Identification of risk loci with shared effects on five major psychiatric disorders: a genome-wide analysis. Lancet. 2013 Apr;381(9875):1371-9.

165 Gandal MJ, Haney JR, Parikshak NN, Leppa V, Ramaswami G, Hartl C, et al.; CommonMind Consortium; PsychENCODE Consortium; iPSYCH-BROAD Working Group. Shared molecular neuropathology across major psychiatric disorders parallels polygenic overlap. Science. 2018 Feb;359(6376): 693-7.

166 Schulze TG, Akula N, Breuer R, Steele J, Nalls MA, Singleton AB, et al.; Bipolar Genome Study. Molecular genetic overlap in bipolar disorder, schizophrenia, and major depressive disorder. World J Biol Psychiatry. 2014 Apr;15(3):200-8.

167 Lichtenstein P, Yip BH, Björk C, Pawitan Y, Cannon TD, Sullivan PF, et al. Common genetic determinants of schizophrenia and bipolar disorder in Swedish families: a population-based study. Lancet. 2009 Jan; 373(9659):234-9.

168 Li L, Chang H, Peng T, Li M, Xiao X. Evidence of AS3MTd2d3-Associated Variants within 10q24.32-33 in the Genetic Risk of Major Affective Disorders. Mol Neuropsychiatry. $2017 \mathrm{Feb} ; 2(4): 213-8$.

169 Liu Z, Huang L, Luo XJ, Wu L, Li M. MAOA Variants and Genetic Susceptibility to Major Psychiatric Disorders. Mol Neurobiol. 2016 Sep;53(7):4319-27.

170 Kendell R, Jablensky A. Distinguishing between the validity and utility of psychiatric diagnoses. Am J Psychiatry. 2003 Jan;160(1): 4-12.

171 Widiger TA, Samuel DB. Diagnostic categories or dimensions? A question for the Diagnostic And Statistical Manual of Mental Disorders - fifth edition. J Abnorm Psychol 2005;114(4):494-504.

172 Burmeister M, McInnis MG, Zöllner S. Psychiatric genetics: progress amid controversy. Nat Rev Genet. 2008 Jul;9(7):527-40.

173 McMahon FJ, Akula N, Schulze TG, Muglia P, Tozzi F, Detera-Wadleigh SD, et al.; Bipolar Disorder Genome Study (BiGS) Consortium. Meta-analysis of genome-wide association data identifies a risk locus for major mood disorders on 3p21.1. Nat Genet. 2010 Feb;42(2):128-31.

174 Sanz-García M, López-Sánchez I, Lazo PA. Proteomics identification of nuclear Ran GTPase as an inhibitor of human VRK1 and VRK2 (vaccinia-related kinase) activities. Mol Cell Proteomics. 2008 Nov;7(11):2199214 .

175 Vázquez-Cedeira M, Lazo PA, Fernández IF, Monsalve DM, Lazo PA. Human VRK2 (vaccinia-related kinase 2) modulates tumor cell invasion by hyperactivation of NFAT1 and expression of cyclooxygenase-2. J Biol Chem. 2012 Dec;287(51):42739-50.

176 Pruim RJ, Welch RP, Sanna S, Teslovich TM, Chines PS, Gliedt TP, et al. LocusZoom: regional visualization of genome-wide association scan results. Bioinformatics. 2010 Sep;26(18):2336-7. 